\title{
An Investigation of the Current Practice to Support Upper Limb Rehabilitation among Advanced Stroke Survivors
}

\author{
Nurul Hafizha Musthafa, Suziah Sulaiman \\ Department of Computer and Information Sciences, Universiti Teknologi PETRONAS, Malaysia
}

\begin{tabular}{l}
\hline \hline Article Info \\
\hline Article history: \\
Received Jan 9, 2018 \\
Revised Mar 2, 2018 \\
Accepted Mar 18, 2018 \\
\hline
\end{tabular}

\section{Keywords:}

Advanced Stroke Survivor

Handwriting

Mobile Application

Stroke Rehabilitation

\begin{abstract}
Stroke rehabilitation helps one to relearn skills lost when a stroke affected part of the brain. Stroke rehabilitation programmes involving technologyassisted physical activities have been employed to complement the conventional practices. The success of such a program lies primarily on how well the current practices are understood, and translated onto the activities planned. This is a challenge to system designers, dealing with the technology, who may have limited access to stroke patients. This paper addresses the issue by investigating the current rehabilitation practices conducted on stroke survivors. The methods involved interviewing the stroke rehabilitation practitioners, and observing how therapy sessions were conducted in a local rehabilitation centre. The study findings revealed that conventional rather than technology-supported methods are still the dominant approach used for stroke rehabilitation. Paper and pencil techniques are still in practice for re-learning how to write among advanced stroke survivors. Similarly, activities with the early and intermediate groups at the rehabilitation centre have not been supported by any computer technology yet. The feedback obtained from the practitioners could be used as a basis to design suitable technology-assisted programs especially for advanced stroke survivors in handwriting activities.
\end{abstract}

Copyright $@ 2018$ Institute of Advanced Engineering and Science. All rights reserved.

\section{Corresponding Author:}

Nurul Hafizha Musthafa,

Department of Computer and Information Sciences,

Universiti Teknologi PETRONAS,

32610 Seri Iskandar, Perak Darul Ridzuan, Malaysia.

Email: nurul_g03590@utp.edu.my

\section{INTRODUCTION}

Stroke is a sudden interruption in the blood supply of the brain. Stroke patients have different level of stroke's condition; thus, making each patient's ability to recovervary. The National Stroke Association of Malaysia (NASAM) has reported that stroke is the third largest causes of death after heart disease and cancer in Malaysia and it is the main cause of severe disability [1]. The latest World Health Organization (WHO) [2] revealed that stroke deaths in Malaysia reached $12.19 \%$ or 15,497 of total deaths and approximately 44 million of individual suffer; disability-adjusted life-year (DALY) from stroke as it may negatively impact on degradation of speech, balancing, vision, coordination and homeostasis [3]. In Malaysia, many stroke cases go untreated or receive late treatment because of the misconception of stroke which is built on lack of information and awareness [1].

Scherbakov et al. [4] reported more than 50\% stroke patients are developing difficulties in economy and social aspects as included in the ATLANTIS, ECASS and NINDS. According to Singh et al. [5], it is predicted an increment of $40 \%$ of stroke admission in local hospital in Malaysia by the year 2020 and motor impairment is the most common implication due to stroke. It is important to understand suitable activities for each level so that an effective stroke rehabilitation programme could be planned. It has been reported that people who participate in a focused programmed perform better than most who do not have stroke 
rehabilitation. This situation creates a challenge to system designers who are techno-savvy but having little knowledge limited access to the stroke patients whenever they want to plan and include suitable technologyassisted activities in the rehabilitation programme.

It is critical to begin rehabilitation early when patients have little to no control over their affected muscles especially the upper limb in order to regain the lost abilities and skills such as moving, lifting, holding, and grab an object. This is because after a stroke, sufferers compensate for motor skills that effect postural stability and body functioning thus leads to long-term consequences such as atrophied muscles [6]. Knowing the fact that, human's handwriting requiring group of muscle to contract and relax concurrently as well as other biological mechanism take place during writing such as language processing, motor planning, spelling, visual spatial motor and so on to produce such a coordination. Stroke and handwriting disability is highly correlated with Agraphia [7]. An overall individual handwriting's skill is likely to further deteriorate with the fact of muscle's ability degradations and thus isolating stroke survivor within the society.

Robot-assisted therapy is one of effective method to conduct a highly repetitive training, taskspecific training and context-specific training [8], [9]. Robot-assisted therapy in rehabilitation allows the therapist to monitor the improvement of motor performance, access motor learning experiments, and provide statistical data [8]. Sivan et al. [10] reported that robot-assisted therapy can supplement the conventional rehabilitation exercise where the physical therapy resource is limited.

Besides, an effective yet safe as well as interactive way of stroke rehabilitation can be induced by implementing Virtual Reality (VR) throughout the session [9], [11], [12]. It also aimed towards the process of neural connection at the affected muscle due to interaction and stimulation of multisensory [9], [12]. The utilization of VR is widely used in rehabilitation programs [6] due to accessibility, cost reduction and technological improvements in software and hardware design [12], [13]. Motivational aspect among stroke survivor towards recovery can be enhanced due to additional enjoyable elements are built throughout simulation-based stroke rehabilitation [5], [9].

World Health Organization (WHO) has conducted a survey where majority were agreed that recent technology, especially mobile application has strong correlation to improve health service globally. Hurst and Tobias [14] stated that smartphones provide a more natural interaction as compared to personal computers for technology-assisted activities. In fact, StrokePad is being used as stroke service by providing stroke clinical assessment at University College London Hospitals [15]. Rand et al. [16] reported that iPad has potential to be used as a self-directed training tool where the individuals are able to practice their hand movement independently and also achieve acceptable upper limb function for better participation in social life. All in all, potential reasons may be highlighted; improving muscle's strength, maintain survivor's interest as well as ubiquitous rehabilitation's resources while turning mobile devices into a post-stroke rehabilitation tools.

This paper presents a study that investigates the current rehabilitation practices conducted on stroke survivors. The objectives are two-fold: (i) to examine the activities conducted during stroke rehabilitation (ii) to identify suitable activities for fine motor skills. The intention is to gather information requirements needed for designing suitable technology-assisted programs especially for hand-writing activity. This is an example of activities that involves repetition, accuracy, and perfection in terms of the prints, which could boost one self satisfaction and esteem. Such positive feelings could help advanced stroke survivors to recover and get back to the society and/ or workforce.

\section{RESEARCH METHOD}

An interview study was carried out to elicit practitioner's perspectives on the current practice used for rehabilitation process among stroke survivors. The interview session was conducted at a stroke rehabilitation centre located in Ipoh. Two practitioners took part in this two-hour study.

The interview session was performed based on a set of questionnaire regarding stroke. It consists of five main questions that are related to guiding and ensuring that the technological development is applicable for stroke rehabilitation. The followings are the questionnaires used for the interview:

a. How would you classify stroke survivor category?

b. What are the possible problems may occur during the rehabilitation process?

c. What are the guidelines on recovery plans indicator for stroke survivors used in this rehabilitation center?

d. Is there any current technology used during the rehabilitation process?

e. What is the most suitable stroke phase to start the handwriting activities? 


\section{RESULTS AND ANALYSIS}

The study findings have been divided into two parts, A and B. Part A addresses the interview questions for question number 1,2,3, and 4 while part B addresses the last interview questions which is question number 5 .

\subsection{General Activities of Stroke Rehabilitation}

This section discusses on the type of activities that are suitable for each category of these stroke survivors. Table 1 presents the general activities conducted during stroke rehabilitation.

Referring to Table 1, the stroke survivors will be divided into three categories which are Early Group, Intermediate Group, and Advanced Group. The Early Group are the stroke survivors who are just being discharged to home, the chronic stroke survivors, and those who need complete dependence of helper. The Intermediate Group are the stroke survivors who are modified dependence, partially need assistance of helper to perform a task. Lastly, the Advanced Group are the stroke survivors who are modified independence or complete independence need of helper.

The second interview question addressed on the possible problem may occur during rehabilitation process. Most of the activities will be conducted in a group of people according to their stroke category and independent level. Some of the stroke survivors who are not suitable for group therapy based on their disability and stroke condition, they will undergo individual session with the practitioner. For individual session, the practitioner also needs to take note on the medical history of the stroke survivor so that the practitioner can take precaution step and the side effect of the drugs taken by the stroke patients before they start the activities. All these three groups of stroke survivors which are Early group, Intermediate group, and the Advanced group will undergo the same activities of muscle strengthening, body balancing, functional exercise, and body assessment in a group assessment session - to relearn and regain their motor skills lost due to brain damage.

Next, the third interview question explains the guideline used at the stroke rehabilitation center. The practitioner stated that the stroke survivors need to go through a standard assessment such as Functional Independence Measure (FIM) and Motor Assessment Scale before being classified into those three categories. The objective of FIM assessment is to record the stroke survivor's ability, disability, and their independence level by completing the task given. Meanwhile, Motor Assessment Scale is the therapist input for the stroke survivor's muscle strengthening, muscle stretching and flexibility, body balancing, and the quality of body movement. Based on the standard assessment, the therapist will suggest the most suitable activities and achievable rehabilitation goal for the stroke survivors.

None of the technology is used during the rehabilitation activities in this stroke rehabilitation center. The practitioner still uses the conventional method to assist them in stroke rehabilitation activities such as rubber ball, weights. Meanwhile, the practitioner stated that some rehabilitation center use the technology for stroke rehabilitation where robotic and applied computational games are used to support their rehabilitation activities, the data is detailed on Table 1.

Table 1. General Activities of Stroke Rehabilitation

\begin{tabular}{|c|c|c|}
\hline \multirow[t]{2}{*}{ Category of Patients } & \multicolumn{2}{|l|}{ Descriptions } \\
\hline & Activities & Technology Used \\
\hline 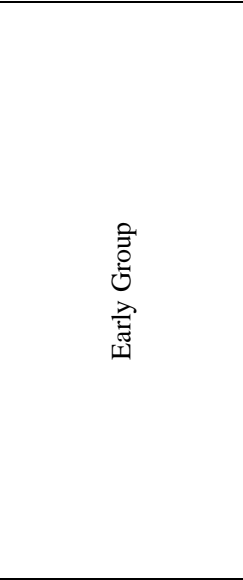 & $\begin{array}{l}\text { Group Assessment: } \\
\text { 1. Muscle strengthening } \\
\text { i. Lift weighting } \\
\text { 2. Body balancing, Body movement } \\
\text { i. Aerobic } \\
\text { ii. Yoga } \\
\text { iii. Body weight } \\
\text { 3. Functional exercise } \\
\text { i. Rubber ball (upper limb) } \\
\text { ii. Knee rolling (lower limb) } \\
\text { 4. Body Assessment } \\
\text { i. Sensory test } \\
\text { ii. Body position } \\
\text { Individual Therapy: } \\
\text { 1. Based on their condition/weakness from standard } \\
\text { assessment. } \\
\text { i. Physical assessment } \\
\text { ii. Medical history. }\end{array}$ & None \\
\hline
\end{tabular}




\begin{tabular}{|c|c|c|}
\hline 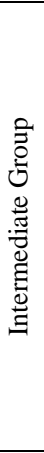 & $\begin{array}{l}\text { Group Assessment: } \\
\text { 1. Muscle strengthening } \\
\text { i. Lift weighting } \\
\text { 2. Body balancing, Body movement } \\
\text { i. Aerobic } \\
\text { ii. Yoga } \\
\text { iii. Body weight } \\
\text { 3. Functional exercise } \\
\text { i. Based on the patient's goal. Eg: grab and hold an } \\
\text { ii. Based. on the patient's independent level/needs. } \\
\text { B. Body Assessment } \\
\text { i. Sensory test } \\
\text { ii. Body position }\end{array}$ & None \\
\hline 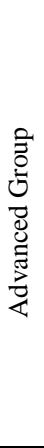 & $\begin{array}{l}\text { Group Assessment: } \\
\text { 1. Muscle strengthening } \\
\text { i. Lift weighting } \\
\text { 2. Body balancing, Body movement } \\
\text { i. Aerobic } \\
\text { ii. Yoga } \\
\text { iii. Body weight } \\
\text { 3. Functional exercise } \\
\text { i. Based on the patient's goal. Eg: writing. } \\
\text { ii. Based on the patient's independent level/needs. } \\
\text { iii. Fine motor movement } \\
\text { 4. Body Assessment } \\
\text { i. Sensory test } \\
\text { ii. Body position }\end{array}$ & None \\
\hline
\end{tabular}

\subsection{The Practitioner's Perspectives for Handwriting Rehabilitation}

This section presents the most suitable stroke survivor's category for handwriting rehabilitation based on practitioner's perspectives.

Based on the interview session, the practitioner suggested that advanced group of stroke survivor is suitable to undergo the writing activity because most of their gross motor movement and muscle tone are good enough. They need to be guided in writing activity as their strength and the ability of fine motor movement are still lacking.

Table 2. Fine Motor Movement for Advanced Stroke Survivor

\begin{tabular}{ccl}
\hline Category of Patients & \multicolumn{1}{c}{ Activities } \\
\hline Advanced & Functional exercise: \\
Group & i. & Based on the patient's goal. \\
& & Eg: writing. \\
& ii. $\quad \begin{array}{l}\text { Based on the patient's } \\
\text { independent level/needs. }\end{array}$ \\
& iii. & Fine motor movement \\
\hline
\end{tabular}

Table 2 is extracted from the information presented in Error! Reference source not found. where this research study focused on the functional exercise needed for advanced stroke survivor. The practitioner stated that the fine motor exercise is most suitable for advanced stroke survivor. Fine motor skills for upper limb consist of small muscle movements such as fingers and wrist. The fine motor is important for upper limb to manipulate, grab and hold small objects. The rehabilitation center uses conventional method for fine motor exercise. Figures 1, 2, and 3 show some of the gadgets used. 


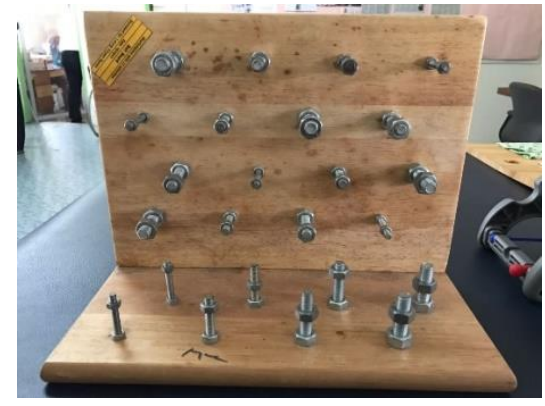

Figure 1. Nuts and Bolts

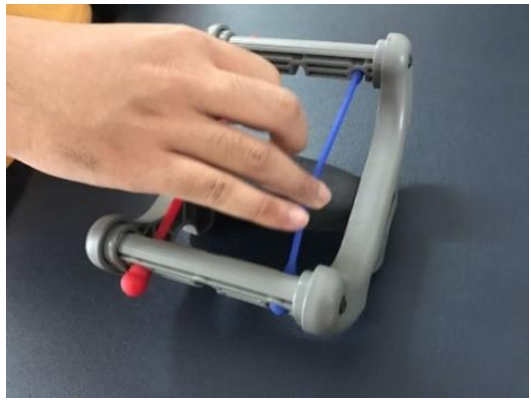

Figure 2. Thera-Band

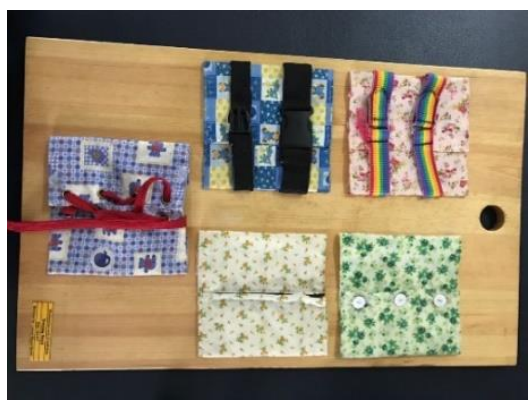

Figure 3. Dressing Board

These fine motor exercises using the gadgets shown in Figures 1, 2, and 3 could help the stroke survivors to strengthen their fine motor muscles so that they are able to grab and hold a pen before learning to write again. Pen and paper method is used for handwriting rehabilitation in this rehabilitation center.

A suitable writing activity also plays an important role where it can give a positive or negative impact on the stroke survivor's writing performance and coordination. For example, a suitable height of the table and their chair position when conducting the writing activity. Some stroke survivors need the hand support to do the writing activity and some of them also might not need the hand support to do the writing activity. The practitioner needs to consider the survivor's requirement and ability during the relearn of writing activities. Then, the practitioner will conduct a test and assessment to analyze their ability, muscle power, writing stabilization and coordination. This is because some of these stroke survivors are able to write, but they have problem in term of hand coordination and stabilization.

\section{CONCLUSION}

This work is devoted to investigate on the current practice of the upper limb rehabilitation for advanced stroke survivors. The research study has gathered the general activities that are suitable for each category of stroke survivors. It has been found in this study that the practitioner suggested advanced group of stroke survivor is suitable to undergo the writing activity.

From the results of the preliminary study, we focused on the advanced stroke survivor because their independence level is high and most of their body movement is fully functional while they are lacking in stamina and fine motor movement. For writing activities, the fine motor is important because the advanced stroke survivors need to hold and grip the pen. This is because the fine motor movement will affect their hand coordination, hand stability and writing performance of the stroke survivors.

To the best of our knowledge, this paper is the first attempt towards designing and developing suitable technology-assisted programs especially for advanced stroke survivors in handwriting activities.

\section{ACKNOWLEDGEMENTS}

We would like to thank our study participants for their participations in the study. This research was supported by Universiti Teknologi PETRONAS, Malaysia. 


\section{REFERENCES}

[1] National Stroke Association of Malaysia. Available from: http://www.nasam.org/.

[2] World Health Organizations. World Health Rankings Malaysia: Stroke. Available from: http://www.worldlifeexpectancy.com/malaysia-stroke.

[3] Mukherjee D, Patil CG. Epidemiology and the global burden of stroke. World neurosurgery. 2011 Dec 31;76(6):S85-90.

[4] Scherbakov N, Von Haehling S, Anker SD, Dirnagl U, Doehner W. Stroke induced Sarcopenia: muscle wasting and disability after stroke. International journal of cardiology. 2013 Dec 10;170(2):89-94.

[5] Singh DK, Nordin NA, Aziz NA, Lim BK, Soh LC. Effects of substituting a portion of standard physiotherapy time with virtual reality games among community-dwelling stroke survivors. BMC neurology. 2013 Dec 13;13(1):199.

[6] Tsatsis CG, Rice KE, Protopopova V. Lateropulsion Rehabilitation Using Virtual Reality for Stroke Patients.

[7] Sinanović O, Mrkonjić Z. Post-stroke writing and reading disorders. Sanamed. 2013;8(1):55-63.

[8] Colombo R, Cusmano I, Sterpi I, Mazzone A, Delconte C, Pisano F. Test-retest reliability of robotic assessment measures for the evaluation of upper limb recovery. IEEE Transactions on Neural Systems and Rehabilitation Engineering. 2014 Sep; 22 (5):1020-9.

[9] Huang X, Naghdy F, Naghdy G, Du H, Todd C. The Combined Effects of Adaptive Control and Virtual Reality on Robot-Assisted Fine Hand Motion Rehabilitation in Chronic Stroke Patients: A Case Study. Journal of Stroke and Cerebrovascular Diseases. 2018 Jan 1; 27 (1):221-8.

[10] Sivan M, O'Connor RJ, Makower S, Levesley M, Bhakta B. Systematic review of outcome measures used in the evaluation of robot-assisted upper limb exercise in stroke. Journal of Rehabilitation Medicine. 2011 Feb 5;43(3):181-9.

[11] Saposnik G, Levin M, Stroke Outcome Research Canada (SORCan) Working Group. Virtual reality in stroke rehabilitation. Stroke. 2011 May 1;42(5):1380-6.

[12] San Luis MA, Atienza RO, San Luis AM. Immersive Virtual Reality as a Supplement in the Rehabilitation Program of Post-Stroke Patients. InNext Generation Mobile Applications, Security and Technologies (NGMAST), 2016 10th International Conference on 2016 Aug 24 (pp. 47-52). IEEE.

[13] Mosadeghi S, Reid MW, Martinez B, Rosen BT, Spiegel BM. Feasibility of an immersive virtual reality intervention for hospitalized patients: an observational cohort study. JMIR mental health. 2016 Apr;3(2).

[14] Neto OM, Peracini AP, da Cunha BC, Rocha AL, Elui VM, Castro PC, da Graca M, Pimentel MD. Architecture for creating mobile assistive products: a case study on posture monitoring of people with motor disability.

[15] Ameer K, Ali K. iPad use in stroke neuro-rehabilitation. Geriatrics. 2017 Jan 6;2(1):2.

[16] Rand D, Schejter-Margalit T, Dudkiewicz I, Kizony R, Zeilig G. The use of the iPad for poststroke hand rehabilitation; a pilot study. InVirtual Rehabilitation (ICVR), 2013 International Conference on 2013 Aug 26 (pp. 109-113). IEEE.

\section{BIOGRAPHIES OF AUTHORS}

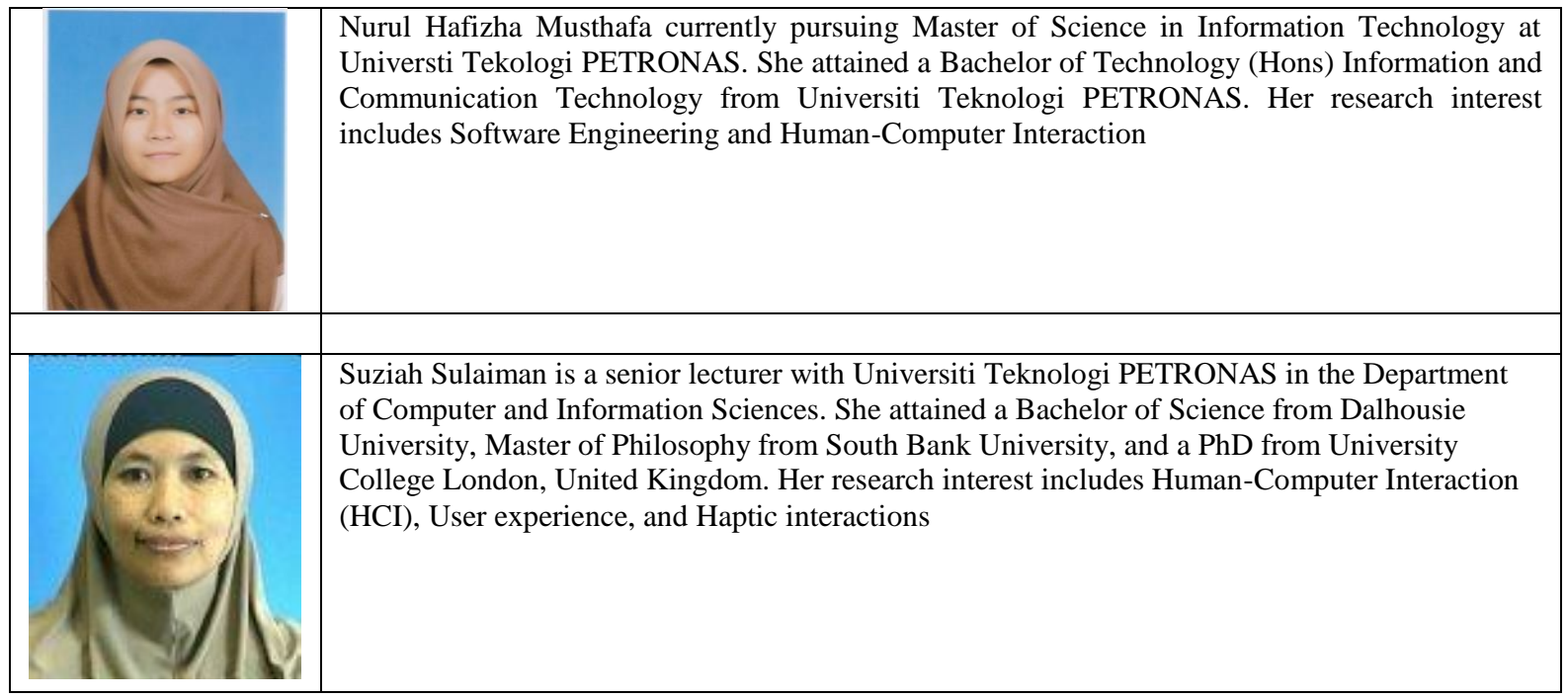

